\title{
Using survey data to assess the distributional effects of trade policy
}

\author{
Guido G. Porto * \\ Development Research Group, The World Bank, MailStop MC3-303, 1818 H Street NW, \\ Washington, DC 20433, United States
}

Received 6 October 2004; accepted 18 September 2005

\begin{abstract}
This paper develops a method to estimate the general equilibrium distributional effects of trade policies using household survey data. Trade reforms cause the domestic prices of traded goods to change and this, in turn, triggers a series of general equilibrium effects. Among these, I estimate the impacts of trade on the prices of traded goods, non-traded goods, and wages. By combining the estimates of the consumption impacts and the labor income impacts, I am able to assess how trade policies affect households across the entire range of the income distribution. An application of the procedure to the study of the distributional effects of Mercosur shows that the average poor and middle-income family in Argentina has benefited from the trade agreement. (C) 2006 Elsevier B.V. All rights reserved.
\end{abstract}

Keywords: Trade reforms; Income distribution; Household welfare

JEL classification: F14; F15; F16; D30

\section{Introduction}

The purpose of this paper is to develop a methodology to empirically explore the effects of trade policies on the distribution of income in developing countries. As opposed to most previous work in the trade literature, which looks at aggregate measures of performance, I use survey data to econometrically assess the impacts of trade reforms. The paper investigates general equilibrium effects, thus extending the existing literature that studies trade liberalization with household data

* Tel.: +1 2024738153 .

E-mail address: gporto@worldbank.org.

URL: http://www.econ.worldbank.org/sta./gporto. 
in partial equilibrium (Attanasio et al., 2004; Deaton, 1989; Edmonds and Pavcnik, 2005; Friedman and Levinsohn, 2002; Goldberg and Pavcnik, 2005). Further, the paper looks at household welfare and formal trade reforms (i.e., tariff reforms), thus complementing previous work on informal barriers and poverty (Porto, 2005).

The methodology used here is based on two links, one connecting trade policies to prices and another connecting prices to household welfare. In the first link, trade reforms in small open economies cause the prices of traded goods to change. In the second link, these price changes affect households as consumers and as income earners. In fact, there are general equilibrium consumption effects, as households pay different prices for traded and non-traded goods, and general equilibrium labor income effects, as factor demand and wages adjust. To measure these welfare impacts, I estimate compensating variations at the household level.

I show that household budget shares approximate the compensating variation originated in the changes in the prices of consumer goods (Deaton, 1989). In addition, I develop methods to estimate the responses of the prices of non-traded goods and wages. To measure the endogenous responses of the prices of non-traded goods, I use time series data to regress the prices of nontraded goods on the exogenous prices of traded goods. To measure the general equilibrium reaction of wages, I estimate wage price-elasticities by using an earnings regression scheme that incorporates the price of traded goods as exogenous regressors (Goldberg and Tracy, 2003; Ravallion, 1990). My method adapts and extends techniques used in demand analysis to the labor market analysis (Deaton, 1997; Wolak, 1996).

The distributional analysis is based on the estimation of the average compensating variations at different levels of per capita household expenditure. The welfare analysis is thus performed across the entire distribution of income. The individual consumption effects of traded goods, the individual consumption effects of non-traded goods and the individual labor income effects are smoothed with non-parametric, locally weighted Fan (1992) regressions. ${ }^{1}$

I apply the methodology to the study of the distributional effects of Mercosur on Argentine families. The experience of Argentina is convenient because it combines enough available data with a changing trade regime during the 1990s. Argentina therefore provides a rich environment, in terms of changes in exogenous parameters and of responses of endogenous variables, to analyze the extent to what individual welfare is affected by trade reforms and to find magnitudes for some of these effects. In addition, since Argentina witnessed an increase in income inequality during the 1990s, I can use the methodology to carry out a comparative distributional analysis of trade policies vis à vis other simultaneous reforms. ${ }^{2}$

The main finding of the paper is that Mercosur benefits the average Argentine household across the entire income distribution. More concretely, there is evidence of a pro-poor bias of the

\footnotetext{
${ }^{1}$ The methods used in this paper differ from the Computable General Equilibrium literature in various ways. CGE models may lead to conclusions that are embedded in assumptions on functional forms rather than being derived from the data (Deaton, 1987, 1997). At the same time, welfare conclusions can be sensitive to small changes in those assumptions (Deaton, 1981). In contrast, my work emphasizes the use of econometric techniques that place few restrictions on estimable parameters, allowing for a much bigger, and better, role for econometric measurement as opposed to assumptions. It will sometimes be necessary to make compromises between a non-parametric analysis and a more restrictive strategy: some parameterization will be needed and even some computation as in the CGE modeling will be unavoidable. My aim is to merge as much econometric measurement with as few theoretical assumptions as possible, in an attempt to provide an analysis with a different flavor from most current research on trade policy.

${ }^{2}$ The Gini coefficient for household per capita income grew from 0.438 in 1992 to 0.480 in 1997 . Raising inequality in Argentina has been very well-documented, in terms of Gini coefficients, Lorenz curves and other relevant instruments (Gasparini, 1999). Financial reforms, economic deregulation and privatization are some of the policy reforms adopted by Argentina.
} 
regional trade agreement: on average, poor households gain more from the reform than middleincome households, whereas the impacts on rich families are positive but not statistically significant. The estimated effects of Mercosur are relatively small, with gains of around $6 \%$ of the initial expenditure at the bottom of the distribution. These results indicate that the tariff reforms of Mercosur are not behind the increase in inequality observed in Argentina during the 1990s. Other simultaneous policies, such as financial reforms, privatization, and deregulation, together with other shocks related to Mercosur, such as the Brazilian devaluation, could play a more decisive role in explaining those trends.

The paper is organized as follows. In Section 2, I introduce a simple general equilibrium trade model of a small open economy to characterize the impacts of trade reforms on prices and to derive measures of the compensating variations at the household level. Section 3 develops the empirical techniques used to estimate these compensating variations and implements the methodology on Argentine data. Section 4 concludes.

\section{The model}

I begin by deriving the set of theoretical distributional effects caused by trade policies that are estimated in this paper. I adapt the small open economy models of Dixit and Norman (1980) and Wooland (1982) to a multi-household context. It is assumed that, for each family, expenditure on consumption goods is equal to income (factor earnings plus transfers). ${ }^{3}$ That is,

$$
e^{j}\left(\mathbf{p}_{\mathbf{T}}, \mathbf{p}_{\mathbf{N T}}, u^{j}\right)=x_{0}^{j}+\sum_{m} w_{m}^{j}+k^{j}+\psi^{j} .
$$

The expenditure function of household $j, e^{j}(\cdot)$, depends on the vector of prices of traded goods $\left(\mathbf{p}_{\mathbf{T}}\right)$, the vector of prices of non-traded goods $\left(\mathbf{p}_{\mathbf{N T}}\right)$, and required utility $u^{j}$. Household income comprises exogenous income, $x_{0}^{j}$, the sum of the labor income of each member $m, w_{m}^{j}$, capital income, $k^{j}$, and government transfers, $\psi^{j}$.

A small open economy faces an exogenous international price $p_{i}^{*}$ for traded good $i$, so that the domestic price $p_{i}$ is given by

$$
p_{i}=p_{i}^{*}\left(1+\tau_{i}\right)
$$

where $\tau_{i}$ is the trade tariff. There are constant returns to scale in the production of these goods and firms participate in competitive markets. Thus, for each good $i$, price is equal to unit production cost

$$
p_{i}=c_{i}(\mathbf{w})
$$

where $c_{i}(\cdot)$ is the unit cost function and $\mathbf{w}$ is the vector of factor prices. The system of equations in (3) characterizes the general equilibrium relationship between the prices of traded goods and the prices of production factors. As product prices change, some sectors expand while some others contract. This causes changes in relative factor demands, depending upon the relative factor intensities used in different sectors. As a result, wages adjust. In a two-good, two-factor model, this relationship is described by the Stolper-Samuelson theorem: an increase in the price of a good causes an increase in the return to the factor intensively used in its production (and a decline in the return to the other factor). However, the association between prices and factor returns is

\footnotetext{
${ }^{3}$ I do not consider the impacts of trade on savings.
} 
more general and multidimensional models only deliver correlations among prices of goods and prices of factors (Dixit and Norman, 1980). ${ }^{4}$

The equilibrium prices of non-traded goods are derived from the demand-supply equality in domestic markets. That is,

$$
\sum_{j} \frac{\partial}{\partial p_{k}} e^{j}\left(\mathbf{p}_{\mathbf{T}}, \mathbf{p}_{\mathbf{N T}}, u^{j}\right)=\frac{\partial}{\partial p_{k}} r\left(\mathbf{p}_{\mathbf{T}}, \mathbf{p}_{\mathbf{N T}}, \mathbf{v}, \phi\right),
$$

where $k$ denotes a non-traded good, $r(\cdot)$ stands for the GDP function of the economy and $\mathbf{v}$ for a vector of factor endowments and $\phi$ is a measure of technical progress (Dixit and Norman, 1980). In Eq. (4), the demand for a non-traded good $k$ is given by the derivative of the expenditure function with respect to the price of that good (Shepard's Lemma), whereas its supply is given by the own-price derivative of the GDP function (Hotelling's Lemma). Given the prices of traded goods, the equilibrium prices of the non-traded goods are endogenously determined by the functions

$$
p_{k}=p_{k}\left(\mathbf{p}_{\mathbf{T}}, \mathbf{v}, \phi, \mathbf{u}\right)
$$

where $\mathbf{u}$ is a vector of utilities.

The welfare evaluation of trade policies comprises two steps: the effects of trade reforms on prices, and the effects of price changes on household welfare. In the first step, vectors of import tariffs $\tau$ are used to identify the trade policy reforms. These tariff reforms cause movements in the domestic prices of the traded goods, according to Eq. (2). In the second step, the price changes trigger two general equilibrium responses: the changes in factor prices given by Eq. (3), particularly wages for workers with varying skills, and the changes in the prices of non-traded goods determined by Eq. (5). The welfare impacts caused by the changes in the consumer prices of traded and non-traded goods are called consumption effects. The welfare impacts caused by the changes in wages are called labor income effects.

The changes in household welfare are computed with measures of compensating variations, the income needed to compensate households for a change in a tariff $\tau_{i}$. These compensations can be measured with the change in exogenous income, $x_{0}^{j}$, that would leave the family indifferent to the pre-policy situation. Differentiating Eq. (1) and assuming public transfers and capital income away, the compensating variation for a change in the tariffs on good $i$ is given by ${ }^{5}$

$$
\frac{\mathrm{d} x_{0}^{j}}{e^{j}}=\left(s_{i}^{j}+\sum_{k \in \mathrm{NT}} s_{k}^{j} \frac{\partial \ln p_{k}}{\partial \ln p_{i}}-\sum_{m} \theta_{m}^{j} \varepsilon_{w m p i}^{j}\right) \frac{\partial \ln p_{i}}{\partial \ln \tau_{i}} \mathrm{~d} \ln \tau_{i},
$$

where $s_{i}^{j}$ is the budget share spent on traded good $i$ by household $j, s_{k}^{j}$ is the budget share spent on non-traded good $k, \theta_{m}^{j}$ is the share of the labor income of member $m$ on total family income. The wage price-elasticities $\varepsilon_{w m p i}^{j}$ capture the proportional change in the wage earned by member $m$ caused by a change in the price of good $i$. Note that Eq. (6) shows the negative of the compensating variation, as a fraction of total initial household expenditure. Thus, the compensating variation is measured, as in Hicks (1939) and Mas-Collel et al. (1995), as the revenue of a hypothetical planner that has to compensate a household for a policy change.

\footnotetext{
4 This means that, with many goods and factors, Stolper-Samuelson effects are not necessarily expected.

${ }^{5}$ In this paper, I do not consider the impacts of trade reforms on government transfers and on non-wage income (profits, returns to specific factors). See Section 3 below.
} 
Accordingly, a positive compensating variation means a positive revenue for the planner, a negative transfer for the household and a welfare gain.

Eq. (6) captures three welfare impacts: the consumption effects of traded goods, the consumption effects of non-traded goods and the labor income effects. The consumption effects of traded goods can be approximated to first order by the budget share $s_{i}^{j}$. The consumption effects of non-traded goods can be approximated by the product of the elasticity of the prices of nontraded goods with respect to the prices of the traded goods $\left(\varepsilon_{p k p i}=\partial \ln p_{k} / \partial \ln p_{i}\right)$ and the respective budget shares $\left(s_{k}^{j}\right)$. The labor income effects can be approximated by the weighted sum across household members of the wage price-elasticities $\left(\varepsilon_{w m p i}^{j}\right)$.

The aim of this paper is to get an estimate of the compensating variation for each household. Some of the terms in Eq. (6) are data, others are estimable parameters, and others are observed policy parameters. The changes in tariffs $\operatorname{dln} \tau_{i}$ represent the policy parameters that can be recovered from the legislation that implements Mercosur. Budget shares, $s_{i}^{j}$ and $s_{k}^{j}$, are data; they can be obtained from expenditure surveys, which are readily available in many developing countries. The induced changes in the prices of traded goods, $\partial \ln p_{i} / \partial \ln \tau_{i}$, and the endogenous responses of the prices of non-traded goods, $\partial \ln p_{k} / \partial \ln p_{i}$, and wages $\varepsilon_{w m p i}^{j}$ need to be estimated.

The compensating variation in Eq. (6) captures first order effects only. Extensions dealing with higher order changes require the estimation of own-price and cross-price demand elasticities, a difficult task given the available data in most developing countries. Since substitution effects are ignored, the welfare effects will be mismeasured. However, as Deaton (1989) points out, the price-elasticities will be irrelevant for the distributional effects, unless demand elasticities are a function of household expenditure. If this is not the case and all households face the same substitution terms, then the absolute welfare effect at the household level will be distorted but the measurement of the relative distributional effects will not be affected.

Another remark is that Eq. (6) is obtained under the assumption of exogenous international prices in a small country. If this were not the case, the first order effects should include additional terms involving the budget shares of other traded goods and the endogenous responses of their prices. Measuring these effects requires, as before, an estimation of the equilibrium response of prices (including both elasticities of demand and of supply) for all traded goods. For most developing countries, the small country assumption can be reasonable so that these issues will not arise.

A different concern with the approximation to the change in labor income arises when factor endowments are endogenous (with fixed factor supply, the compensating variation in Eq. (6) is properly measured). Here, as in the case of the substitution terms in consumption, there can be mismeasurement in the distributional effects if the supply of labor (or the consumption of leisure) responds to product price changes. The total welfare effect will be mismeasured to an extent given by the elasticity of hours worked, but the relative impact on household well-being will not be affected if this elasticity does not vary across levels of income.

\section{The distributional effects}

This section describes the methods used to assess the distributional effects of trade policies in Argentina. Specifically, I investigate the welfare effects of adopting Mercosur, a regional trade agreement among Argentina, Brazil, Paraguay and Uruguay. ${ }^{6}$ I introduce the econometric

\footnotetext{
${ }^{6}$ The methodology could also be applied to other actual or hypothetical trade reforms, such as unilateral trade liberalization.
} 
techniques that are needed to estimate each of the different components of the compensating variations at the household level, Eq. (6). I describe how to recover the changes in the prices of the traded goods (Section 3.1) and how to analyze the consumption effects of traded goods (Section 3.2) and non-traded goods (Section 3.3). Section 3.4 explains how to estimate the changes in wages and the labor income effects. The household total compensating variations including all these effects are studied in Section 3.5.

\subsection{Price changes of traded goods}

The main characteristic of this paper is the measurement of the welfare effects of trade policies in general equilibrium, a task that requires comparable consumption and labor income effects for a given family. To study the consumption effects, I need data on budget shares, which are available in the National Household Expenditure Survey (ENGH). This is a comprehensive expenditure survey in Argentina that adopts a specific classification of consumption goods which includes four traded goods and three non-traded goods. The traded goods are Food and Beverages, Clothing, House Equipment and Maintenance Goods, and Other Traded Goods. The non-traded goods are Housing, Transport and Communication, Health and Education, and Leisure related Goods. ${ }^{7}$ This classification of goods is adopted in this paper.

To estimate the impacts of Mercosur on prices, I look at the effects of the elimination of tariff barriers among country members and the implementation of common external tariffs on the rest of the world, the main reforms introduced by the regional trade agreement. For each traded good $i$, these impacts correspond to the term $\left(\partial \ln p_{i} / \partial \ln \tau_{i}\right) d \ln \tau_{i}$ in Eq. (6). I assume that Argentina is a small country that faces exogenous prices of traded goods. In order to accommodate the discriminatory tariffs applied by Mercosur and the cross-hauling prevalent in trade data, I introduce regional differentiation across goods, in the tradition of the Armington (1969) model. Specifically, I follow Whalley (1985) and Shoven and Whalley (1992) and assume that products are differentiated by large trading blocks (North America, Western Europe, Eastern Europe, Asia, Latin America, and Other).

The price index for traded good $i, p_{i}$, is defined as an import-share weighted average of the price of the varieties coming from each of these regions. Let $\tau_{i m}$ be the intrazone tariff on Mercosur members, and let $\tau_{i r w}$ be the common external tariff on all other varieties. The change in the (logarithmic) price of good $i$ is given by

$$
\mathrm{d} \ln p_{i}=\theta_{i m} \mathrm{~d} \ln \left(1+\tau_{i m}\right)+\theta_{i r w} \mathrm{~d} \ln \left(1+\tau_{i r w}\right),
$$

where the weights are the fraction of imports of a good $i$ coming from Mercosur members $\left(\theta_{\text {im }}\right)$, and the fraction of imports coming from the rest of the world $\left(\theta_{i r w}\right)$. Using data on import shares, intrazone tariffs and common external tariffs, I use Eq. (7) to compute the price changes originated in Mercosur. In Eq. (7), I assume a unitary pass-through rate from tariffs to prices. In the empirical application below, I also perform a sensitivity analysis based on different passthrough rates for different goods.

The data on the tariffs levied on each of the four traded goods before and after Mercosur are listed in Table 1. In 1992 (before Mercosur), there is some fair degree of protection (column 1).

\footnotetext{
${ }^{7}$ The ENGH survey collects data on over ninety goods. The aggregation used here exploits the availability of price indices for traded and non-traded goods published by the National Institute of Statistics and Censuses in Argentina. See Appendix A for more details.
} 
Table 1

Tariff structure and price changes Mercosur

\begin{tabular}{|c|c|c|c|c|}
\hline & Tariff 1992 & Intrazone tariff 1996 & Common external tariff 1996 & Price change Mercosur \\
\hline & (1) & (2) & (3) & (4) \\
\hline Food and beverages & 6.9 & 0.05 & 13.7 & 1.4 \\
\hline Clothing & 20.4 & 3.3 & 17.9 & -6.4 \\
\hline $\begin{array}{l}\text { House equipment and } \\
\text { maintenance goods }\end{array}$ & 16.1 & 0.05 & 14.2 & -5.4 \\
\hline Other traded goods & 12.7 & 0.05 & 11.7 & -3.2 \\
\hline
\end{tabular}

Computations based on tariffs rates taken from the Argentine legislation (Decrees 2657/91 and 998/95). There is an average import tax characterizing the baseline situation in 1992 (column 1). Mercosur implemented an Intrazone Tariff (column 2) and a Common External Tariff on imports coming from the rest of the world (column 3).

The price changes in columns 4 are computed according to Eq. (7) in the text.

The average tariff on imports of Clothing is $20.4 \%$, the highest. House Equipment gets a $16.1 \%$ tariff and Other Goods, 12.7\%. The lowest average rate is on Food and Beverages, 6.9\%. The intrazone tariff (column 2) decreases to zero for all goods but Clothing, which gets a $3.3 \%$ tax. There is also some protection granted by the common external tariff (column 3). The rate on Food and Beverages is $13.7 \%$, twice the pre-Mercosur rate. The tariffs on the remaining three goods are slightly lower than in 1992, 17.9\% (on Clothing), 14.2\% (on House Equipment) and 11.7\% (on Other Goods).

Column (4) of Table 1 shows my estimates of the total changes in the prices of traded goods caused by Mercosur (Eq. (7)). The price of Food and Beverages increases by $1.4 \%$; instead, the prices of Clothing, House Equipment and Other Goods decline by 6.4\%, 5.4\% and 3.2\%, respectively. These are the main price changes for the first link of my methodology.

\subsection{The consumption effects of traded goods}

I investigate next the consumption effects of traded goods, which are given by the term $s_{i}^{j}$ $\left(\partial \ln p_{i} / \partial \ln \tau_{i}\right) d \ln \tau_{i}$ in Eq. (6). To measure these terms, I need data on the budget share spent on these goods by each Argentine household. The National Household Expenditure Survey (ENGH) provides this information. ${ }^{8}$

The households interviewed in the ENGH survey comprise the baseline sample used in my distributional analysis. For each of these households, I measure the consumption effects of traded goods by multiplying the budget share $s_{i}^{j}$ and the price changes induced by Mercosur $\left(\partial \ln p_{i} / \partial \ln \tau_{i}\right)$ $\mathrm{d} \ln \tau_{i}$ (Section 3.1). I use these household welfare effects to study the distributional effects of trade policies across the entire distribution of income. Since there are 21,127 households in the expenditure survey (ENGH), I need a procedure to summarize all this information in a useful way. To do this, I estimate average welfare effects at different points along the per capita expenditure spectrum. These averages are the right measures for my distributional purpose since they reflect the marginal effect of a price change on a hypothetical social welfare function (Deaton, 1989).

One way to compute these conditional averages is to estimate a parametric linear regression of the welfare effects - the compensating variations $\mathrm{cv}^{j}$ defined by Eq. (6) - on the logarithm of per capita household expenditure $\left(x^{j}\right)$. This would define the conditional expectation as $E\left[\mathrm{cv}^{j} \mid x^{j}\right]=b_{1}+b_{2} x^{j}$, where $b_{1}$ and $b_{2}$ are estimable parameters. The distributional analysis can

\footnotetext{
${ }^{8}$ See Appendix A for details on the ENGH survey.
} 
be performed by plotting a line, $\hat{E}[\mathrm{cv} \mid x]=\hat{b}_{1}+\hat{b}_{2} x$, using the OLS coefficients $\hat{b}_{1}$ and $\hat{b}_{2}$ to predict the regression function.

One problem with this approach is that the fit can be poor if the relationship between local changes in household welfare and per capita household expenditure is nonlinear. In these cases, the details of the statistical association between the household welfare effects and the logarithm of per capita expenditure can be more suitably explored with a non-parametric procedure. Nonparametric regressions allow the data to choose the best local shape of the regression function $m(x)=E[Y \mid X=x]$, thereby reducing the biases inherent in the global fit.

In what follows, I use locally weighted regressions (Fan, 1992). Conceptually, I run different linear (or polynomial) regressions of the welfare effects on the logarithm of per capita expenditure using only local data points. At each point in the support of the log per capita household expenditure $(x)$, I carry out the following program (Fan, 1992)

$$
\min _{\phi_{1}, \phi_{2}} \sum_{j} \omega^{j}\left(\mathrm{cv}^{j}-\phi_{1}-\phi_{2} x^{j}\right)^{2} K\left(\frac{x^{j}-x}{h}\right),
$$

where $\mathrm{cv}^{j}$ is the compensating variation accruing to household $j, K(\cdot)$ is a Gaussian Kernel function, and $h$ is the bandwidth that defines the local data to be used in the non-parametric regression. In Eq. (8), I have introduced sampling weights for household $j, \omega^{j}$, that are used to correct biases (due to sample design or differential response, for instance) so that the sample is representative of the population. The average compensating variation at each level of income can be estimated by $m(x)=\hat{\phi}_{1}+\hat{\phi}_{2} x$.

The consumption effects of traded goods caused by Mercosur are plotted in Fig. 1. The solid line plots the average welfare effect conditional on the level of per capita household expenditure, computed with the Fan regressions (8). The broken lines plot the confidence bands, computed with a bootstrap procedure. In the case of the consumption effects of traded goods, the source of randomness is the sampling variability of households (and therefore of budget shares) in the expenditure survey. To get the confidence bands, I take random samples of households from the

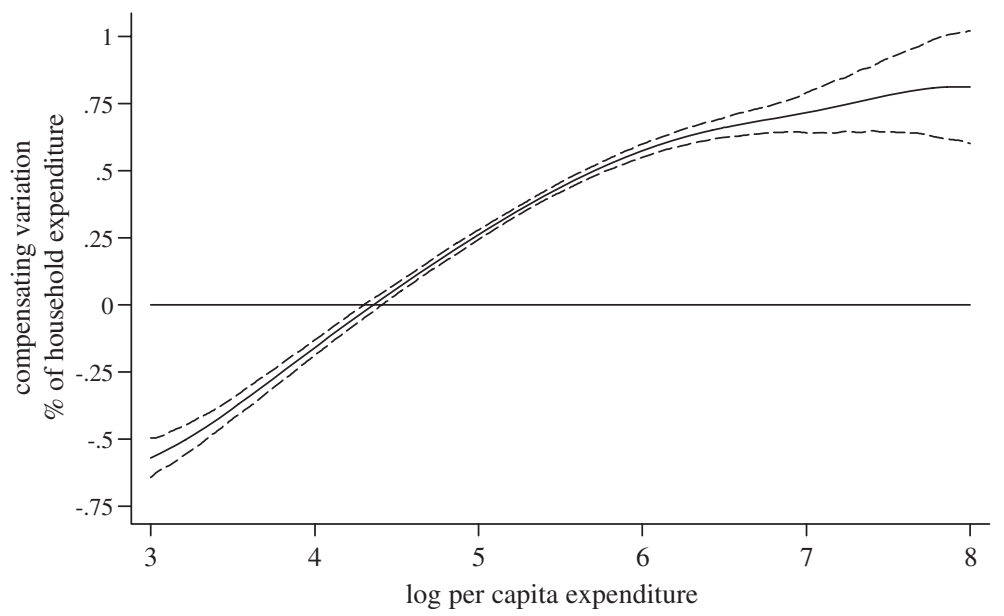

Fig. 1. Consumption effects of traded goods. Notes: the solid line shows the average consumption effects of traded goods. The curve is estimated with locally weighted non-parametric regression (Fan, 1992). The broken lines report the 5\% confidence bands of the average consumption effects. These bands are estimated with bootstrap methods. 
ENGH survey and I recompute the Fan regressions. The confidence bands are built using the standard error (approximated with the interquantile range) of the estimated regression functions, after repeating the procedure two hundred times. In all the following figures, I measure household per capita expenditure in monthly dollars (expressed in logs).

Fig. 1 shows the total consumption effects caused by the joint change in the price of the four traded goods. The estimated compensating variation curve is upward sloping, indicating a prorich bias. For middle-income and rich households, the average consumption effect is found to be positive, and significantly different from zero. In contrast, I find significant welfare losses for the poorest households in Argentina. The gains extend to $0.75 \%$ of initial household expenditure; the losses amount to less than $0.5 \%$ of expenditure. There is simple intuition for these results. The Mercosur-induced increase in the price of Food and Beverages produces negative average compensating variations that are larger for the poorest households (due to Engel Law). For the poor, in fact, these losses dominate the gains generated by the declines in the prices of the remaining traded goods, the net effect being negative as a result. For middle-income and rich households, the opposite is true.

\subsection{Consumption effects on non-traded goods}

The consumption effects of non-traded goods are given by the terms $\sum_{k}\left(\partial \ln p_{k} / \partial \ln p_{i}\right)\left(\partial \ln p_{i} /\right.$ $\left.\partial \ln \tau_{i}\right) d \ln \tau_{i}$ in Eq. (6). Their estimation requires multiplying the household budget shares in the ENGH expenditure survey $\left(s_{k}^{j}\right)$, the change in the prices of the traded goods (Section 3.1) and the endogenous responses of the prices of non-traded goods $\left(\partial \ln p_{k} / \partial \ln p_{i}\right)$, which need to be estimated.

\subsubsection{Price changes of non-traded goods}

In Section 2, I showed that the prices of the non-traded goods $k$, (Housing, Transport and Communication, Health and Education and Leisure Goods), are a function of the exogenously given prices of the traded goods. That is

$$
p_{k}=p_{k}\left(p_{\mathrm{FB}}, p_{\mathrm{C}}, p_{\mathrm{EQ}}, p_{\mathrm{OG}}, \mathbf{v}, \phi\right),
$$

where $p_{\mathrm{FB}}, p_{\mathrm{C}}, p_{\mathrm{EQ}}$ and $p_{\mathrm{OG}}$ are the prices of Food and Beverages, Clothing, House Equipment and Other Goods, respectively. Eq. (9) can be estimated using time series data on monthly prices from 1992 to $1999 .{ }^{9}$ To introduce some dynamics in price adjustment, I define

$$
p_{k}=p_{k 1}\left(p_{\mathrm{FB} t}, p_{\mathrm{C} t}, p_{\mathrm{EQ} t}, p_{\mathrm{OG} t}\right)+p_{k 2}\left(p_{\mathrm{FB} t-1}, p_{\mathrm{C} t-1}, p_{\mathrm{EQ} t-1}, p_{\mathrm{OG} t-1}\right) .
$$

To estimate a flexible function form, I approximate the functions $p_{k 1}(\cdot)$ and $p_{k 2}(\cdot)$ with a Taylor expansion so that the model is

$$
\begin{aligned}
\log p_{k t}= & a_{00}+\sum_{i \in T} a_{0 i} \log p_{i t}+\frac{1}{2} \sum_{i \in T} \sum_{i^{\prime} \in T} a_{i i} \log p_{i t} \log p_{i t}+\sum_{i \in T} b_{0 i} \log p_{i t-1} \\
& +\frac{1}{2} \sum_{i \in T} \sum_{i^{\prime} \in T} b_{i i} \log p_{i t-1} \log p_{i t^{\prime}-1}+\mathbf{c}_{\mathbf{t}}^{\prime} \gamma_{\mathbf{c}}+\mu_{t} .
\end{aligned}
$$

In Eq. (11), I regress the monthly prices of each non-traded good $p_{k}$ on the monthly prices (current and lagged) of the four traded goods (plus interactions at $t$ and $t-1$ separately); $\mu_{t}$ is an

\footnotetext{
${ }^{9}$ Appendix A describes the price data.
} 
error term. To account for the role of technical progress and factor endowments, I include year dummies and time trends in the vector of controls $\mathbf{c}_{\mathbf{t}}$.

To avoid the problem of spurious regression, I follow the usual practice of estimating the model in first differences. ${ }^{10}$ Prior to estimation, I introduce the restrictions imposed by theory: homogeneity of degree one in prices and symmetry $\left(a_{i i^{\prime}}=a_{i^{\prime} i} ; b_{i i^{\prime}}=b_{i^{\prime} i}\right)$ require that $\sum_{i \in T} a_{0 i}+$ $\sum_{i \in T} b_{0 i}=1, \sum_{i \in T} a_{i k}=0, \sum_{i \in T} b_{i k}=0, \sum_{i^{\prime} \in T} a_{i i^{\prime}}=0$, and $\sum_{i^{\prime} \in T} b_{i^{\prime} i}=0$. I consistently estimate the variance of the coefficients using the Newey-West correction for autocorrelation in the residuals, using twelve lags.

Table 2 reports the estimated elasticities for two regression models per price of non-traded good, one with year dummies and a trend and another with year dummies only. There are only minor differences in these two specifications. The price of Housing, Transport and Communication is positively related to the prices of Food and Beverages, Clothing and Other Goods, and negatively related to the price of House Equipment. The price of Health and Education reacts negatively to changes in the prices of Food and Beverages and Clothing, and positively to changes in the price of House Equipment and Other Goods. Finally, there is a negative relationship between the prices of Leisure Goods and Clothing, and a positive association with the prices of Food and Beverages, House Equipment and Other Goods.

Since I am estimating complex, general equilibrium relationships, there are no theoretical predictions. Correlations are not transitive and thus the elasticities in Table 2 can show any sign (Dixit and Norman, 1980). Nevertheless, I argue that the coefficients pass the following intuitive test. Suppose, as it is the case, that Food and Beverages and Clothing are intensive in unskilled labor relative to House Equipment. Similarly, assume that Health and Education is intensive in skilled labor relative to Housing, Transport and Communication. ${ }^{11}$ Then, increases in the relative prices of Food and Beverages and Clothing would generate an increase in the relative wage of unskilled labor and, hence, a decrease in the price of Health and Education and an increase in the price of Housing, Transport and Communication. Similarly, increases in the price of House Equipment would generate an increase in the relative wage of skilled workers and an increase in the price of Health and Education and a decrease in the price of Housing, Transport and Communication. These are, in principle, the essence of my findings in Table 2.

The last row in Table 2 shows the total change in the index price of each of the non-traded goods that can be attributed to Mercosur. For each category of non-traded goods $k$, I compute $\sum_{i} \hat{\varepsilon}_{p k p i} \mathrm{~d} \ln p_{i}$, using the predicted change in the prices of traded goods (column 4 of Table 1) and the estimated relationship between the prices of traded and non-traded goods (Table 2). I estimate that Mercosur effects a decrease in the price of all three categories of goods: that of Housing, Transport and Communication, by $0.9 \%$, that of Health and Education, by $4.4 \%$ and that of Leisure Goods, by $4 \%$ (the latter two being significant).

\subsubsection{The distributional effects}

I turn next to the estimation of the average distributional effects at different levels of income using the locally weighted non-parametric regressions. In Fig. 2, the continuous solid line plots the average welfare effect and the broken lines, the confidence bands. In the case of the consumption effects on non-traded goods, there are two sources of randomness: the sampling variability of budget shares and the estimation of the responses of the prices of non-traded goods. To jointly account for these sources of variability, I use bootstrap methods as follows.

\footnotetext{
${ }^{10}$ I cannot reject the hypothesis that the series involved in the regressions are I(1) according to standard tests.

11 See Table 4 below for evidence on these factor intensities.
} 
Table 2

The responses of the prices of non-traded goods Argentina

\begin{tabular}{|c|c|c|c|c|c|c|}
\hline & \multicolumn{2}{|c|}{$\begin{array}{l}\text { Housing, transport } \\
\text { and communications }\end{array}$} & \multicolumn{2}{|c|}{ Health and education } & \multicolumn{2}{|c|}{ Leisure goods } \\
\hline & (1) & (2) & (1) & (2) & (1) & (2) \\
\hline \multirow[t]{2}{*}{ Food and beverages } & 0.469 & 0.484 & -0.049 & -0.020 & 0.064 & 0.129 \\
\hline & 5.056 & 5.582 & -0.752 & -0.349 & 1.024 & 2.143 \\
\hline \multirow[t]{2}{*}{ Clothing } & 0.237 & 0.250 & -0.225 & -0.201 & -0.270 & -0.216 \\
\hline & 1.192 & 1.088 & -2.021 & -1.809 & -3.934 & -2.501 \\
\hline \multirow[t]{2}{*}{ House equipment } & -0.413 & -0.427 & 0.775 & 0.748 & 0.890 & 0.831 \\
\hline & -1.522 & -1.476 & 3.722 & 3.486 & 2.865 & 2.647 \\
\hline \multirow[t]{2}{*}{ Other goods } & 0.707 & 0.693 & 0.500 & 0.473 & 0.316 & 0.257 \\
\hline & 2.535 & 2.408 & 2.006 & 1.988 & 0.956 & 0.785 \\
\hline Wald test & 13.79 & 13.86 & 65.79 & 55.08 & 24.66 & 34.43 \\
\hline \multirow[t]{2}{*}{ Price change due to Mercosur ( $t$-test) } & -0.9 & & -4.4 & & -4.0 & \\
\hline & -0.2 & & -2.1 & & -1.9 & \\
\hline
\end{tabular}

The prices of the three non-traded goods are regressed on the prices of the four traded goods using a time series of monthly prices from 1992 to 1999 . A translog specification is used to estimate the elasticities shown in the table. The regressions were run using first differenced price series to avoid spurious correlation. For each price of non-traded, column 1 includes year dummies and a trend and column 2 includes year dummies only.

Coefficients in bold. $t$-statistics in italics.

In each replication of the bootstrap loop, I resample from the ENGH household expenditure survey. This step accounts for the random variation in budget shares. To deal with the variance of the estimated elasticities, I resample from their empirical asymptotic distribution. The model in Eq. (11) delivers a vector of coefficients $\hat{\boldsymbol{\beta}}_{\mathbf{1}}$ and a covariance matrix $\hat{\boldsymbol{\Omega}}_{\mathbf{1}}$, such that $\hat{\boldsymbol{\beta}}_{\mathbf{1}} \rightarrow{ }^{d} N\left(\boldsymbol{\beta}_{\mathbf{1}}, \boldsymbol{\Omega}_{\mathbf{1}}\right)$, where $\boldsymbol{\beta}_{\mathbf{1}}$ is the true vector of parameters and $\boldsymbol{\Omega}_{\mathbf{1}}$ is its asymptotic variance. ${ }^{12}$ In each loop, I obtain a new set of elasticities for non-traded goods that are assigned to the resampled ENGH households. The Fan regression is run on the bootstrapped sample to deliver a new estimate of the average welfare effects. After 200 replications, I compute the standard error of the estimated regression functions to build the confidence bands.

In Fig. 2, the aggregate average compensating variations are positive, and significantly different from zero, at (almost) all income levels. ${ }^{13}$ The gains are also increasing in the logarithm of per capita expenditure, suggesting a pro-rich bias. The compensations range from over $0.3 \%$ to over $1 \%$ of initial household expenditure, being therefore similar in magnitude to those found for the case of traded goods. This result highlights the importance of non-traded goods in the aggregate consumption effects, a topic that has never been addressed before in the related literature.

The following explanation accounts for these pro-rich consumption effects of non-traded goods. The average compensating variation for Housing, Transport and Communication is not significantly different from zero at any income level because its Engel curve (for budget shares) is relatively flat and the Mercosur-induced decline in its price is statistically insignificant. In contrast, the budget-share Engel curves for Health and Education and Leisure Goods slope

\footnotetext{
${ }^{12}$ To do the resampling in practice, I define $\boldsymbol{\beta}_{\mathbf{1}}^{\mathbf{0}}$ as random vector of draws from $N(\mathbf{0}, \mathbf{I})$ and $\mathbf{R}_{\mathbf{1}}$ as the Cholesky decomposition of $\hat{\boldsymbol{\Omega}}_{\mathbf{1}}$. I compute $\mathbf{R}_{\mathbf{1}} \boldsymbol{\beta}_{\mathbf{1}}^{\mathbf{0}}+\hat{\boldsymbol{\beta}}_{\mathbf{1}} \sim N\left(\hat{\boldsymbol{\beta}}_{\mathbf{1}}, \hat{\boldsymbol{\Omega}}_{\mathbf{1}}\right)$.

${ }^{13}$ Notice that the confidence bands are wider than those found in Fig. 1 because of the additional error introduced by the estimated non-traded price-elasticities.
} 


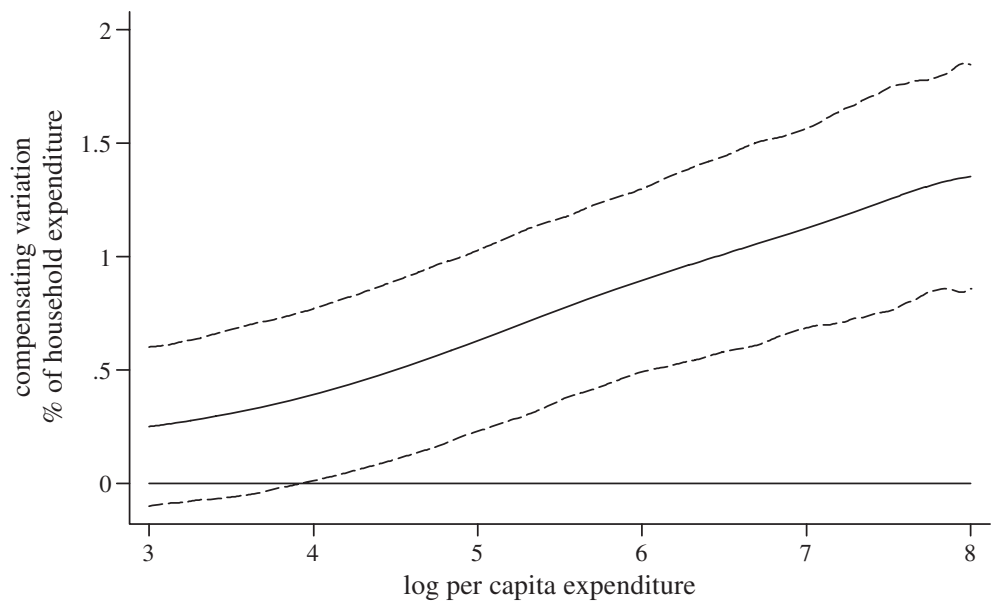

Fig. 2. Consumption effects of non-traded goods. Notes: the solid line shows the average consumption effects of nontraded goods. The curve is estimated with locally weighted non-parametric regression (Fan, 1992). The broken lines report the $5 \%$ confidence bands of the average consumption effects. These bands are estimated with bootstrap methods (see text).

strongly upwards (from nearly 0 percent at the bottom of the income distribution to nearly $10 \%$ at the upper end) and the Mercosur-induced changes in prices are statistically significant (Table 2). These facts produce upward sloping and significant distributional effects.

\subsection{Labor income effects}

This section assesses the labor income effects of Mercosur, which are given by the term $\varepsilon_{w m p i}^{j}\left(\partial \ln p_{i} / \partial \ln \tau_{i}\right) \mathrm{d} \ln \tau_{i}$ in Eq. (6). The key component of these labor income impacts is the wage price-elasticities, which are estimated next.

\subsubsection{Estimation of the wage elasticities}

In the model of Section 2, wages $w^{j}$ are a function of the prices of the traded goods $\left(\mathbf{p}_{\mathbf{T}}^{j}\right)$ and other determinants $\mathbf{z}^{\mathbf{j}}$. That is,

$$
w^{j}=w^{j}\left(\mathbf{p}_{\mathbf{T}}^{j}, \mathbf{z}^{\mathbf{j}}\right) .
$$

In what follows, I estimate Eq. (12) by using household survey data. In Argentina, these data are available in the Permanent Household Survey (Encuesta Permanente de Hogares, EPH), a labor market survey with information on wages, employment, hours worked, and individual and household characteristics. ${ }^{14}$

One problem of using survey data on wages in a regression that includes product prices of traded goods as exogenous regressors is the lack of price variability at the household level. ${ }^{15}$ To deal with this problem, I propose to identify the wage price-elasticities by exploiting the time variability in prices and the time variability in surveys. My method is related to techniques used in

\footnotetext{
${ }^{14}$ The data are described in detail in Appendix B.

15 Notice, however, that having household prices is problematic as well. If these prices (usually unit values) contain quality information, they may be endogenous, thus leading to inconsistent estimates.
} 
demand analysis, such as that of Deaton's (1997), who exploits the regional variability in unit values to estimate systems of demand parameters, and of Wolak's (1996), who uses the time variation in CPS surveys and prices to recover those parameters. Similarly, Goldberg and Tracy (2003) estimate wage responses to changes in exchange rates by using the time variability of CPS surveys in the United States, and Ravallion (1990) estimate the responses of rural wages to changes in food prices in Bangladesh. The procedure proposed here extends these techniques to the estimation of the wage price-elasticities needed to assess trade policies.

In order to exploit the time variability of prices, I need repeated cross sections of household surveys. In Argentina, the Encuesta Permanente de Hogares (EPH) is gathered in May and October of every year. Thus, I can use a time series of sixteen surveys from 1992 to 1999 (two per year) to identify the elasticities. ${ }^{16}$

The responses of factor prices to changes in product prices vary by factor due to differences in relative factor intensities across sectors. I capture heterogeneous wage responses by considering that workers supply different types of labor services depending upon their educational attainment. It is assumed that there exist three different types of labor in the economy: unskilled labor (comprising workers with only primary education), semiskilled labor (including those with completed secondary school), and skilled labor (comprising those workers with a college degree). The estimating equation is

$$
\log w^{j}=\sum_{i \in T} \log p_{i}^{j}\left(\mathbf{e}^{\mathbf{j}^{\prime}} \boldsymbol{\beta}_{\mathbf{i}}\right)+\mathbf{e}^{\mathbf{j}^{\prime} \mathbf{d}}+\mathbf{z}^{\mathbf{j}^{\prime}} \boldsymbol{\gamma}+\varepsilon^{j},
$$

where $\mathbf{e}^{\mathbf{j}^{\prime}}$ stands for a vector representing the $j$ th row of the matrix of dummy variables for educational attainments (primary, secondary, college), and $\beta_{i}$ is the vector of coefficients that captures the differential impact of price $p_{i}$ on wages. In Eq. (13), the logarithm of the wage earned by individual $j$ is regressed on a set of exogenous variables $\mathbf{z}^{j}$ (age, age squared, gender and marital status), education dummies, and the log prices of the traded goods interacted with the education dummies. The regression also includes a time trend to control for the eventual role of technical change and factor supplies. The last term $\varepsilon^{j}$ represents a disturbance error.

The model can be consistently estimated with ordinary least squares since prices for traded goods are exogenously set in world markets. ${ }^{17}$ Before estimation, I impose homogeneity of degree one in prices for the different labor demands. The estimation of the standard errors has to take into account the clustering effects that may arise when aggregate variables (like prices) are used to explain a microvariable (Kloek, 1981). Clustering effects are corrected by using a robust procedure that modifies the Huber-White formulas for heteroskedasticity.

Results are listed in Table 3, which includes twelve wage price-elasticities, three responses for each of the prices of the four traded goods. The price of Food and Beverages shows a positive association with the wages of low-education workers (with elasticities of 2.06 for unskilled workers and 0.12 for semiskilled workers) and a negative association with the wages of higheducation workers (with an elasticity of -1.42). These goods appear to be produced with relative low-skill intensive techniques of production. ${ }^{18}$ The elasticities are statistically significant for unskilled and skilled workers.

\footnotetext{
${ }^{16}$ I use the 1992-1999 data because the period before 1992 was characterized by inflation and macroeconomic imbalances and the period after 1999 by a severe recession and financial crisis.

17 To account for the endogeneity of the trade reform, I run separate regressions using domestic prices and international prices, which are exogenous, as regressors. The coefficients estimated with these two models were statistically similar, indicating that Eq. (13) delivers consistent wage price-elasticities.

${ }^{18}$ Evidence that supports this statement is given in Table 4. See below.
} 
Table 3

Wage responses to changes in prices of traded goods educational categories of labor Argentina

\begin{tabular}{lcccc}
\hline & Food and beverages & Clothing & House equipment & Other goods \\
\hline Primary education (unskilled labor) & $\mathbf{2 . 0 6}$ & $\mathbf{1 . 1 9}$ & $\mathbf{- 2 . 0 2}$ & $-\mathbf{0 . 2 2}$ \\
& 7.22 & 2.08 & -2.99 & -0.98 \\
Secondary education (semiskilled labor) & $\mathbf{0 . 1 2}$ & $-\mathbf{1 . 8 0}$ & $\mathbf{1 . 9 2}$ & $\mathbf{0 . 7 6}$ \\
& 0.44 & -3.26 & 2.91 & 3.43 \\
College education (skilled labor) & $-\mathbf{1 . 4 2}$ & $-\mathbf{5 . 0 5}$ & $\mathbf{6 . 0 4}$ & $\mathbf{1 . 4 2}$ \\
& -3.77 & -6.65 & 6.99 & 4.42 \\
$R^{2}$ of the Regression & 0.34 & & & \\
\hline
\end{tabular}

For each of the three different educational attainments, the table shows the response of wages to changes in the prices of four traded goods. Using data from the Permanent Household Survey, the log of monthly wages is regressed on the log of prices interacted with educational dummies. The regression includes the following controls: age, age squared, gender and marital status, education dummies and time trends.

The cluster-corrected $t$-statistics are reported in italics below the coefficients.

Changes in the price of Clothing impact negatively and significantly on the wages of highskilled individuals (with an elasticity of -5.05) and semiskilled workers (with an elasticity of -1.8). In contrast, the response of the wage of low-skilled workers is positive (1.19) and significant. These findings support the idea that textiles are intensive in low-skilled labor.

The price of House Equipment is positively and significantly associated with the wages of skilled workers (with an elasticity of 6.04) and semiskilled workers (with an elasticity of 1.92). For unskilled workers, I find a negative and significant association between wages and prices. These findings suggest that House Equipment and Maintenance Goods is a relatively skill intensive product category.

The price of Other Goods impacts positively and significantly on the wages of semiskilled and skilled workers, and negatively but insignificantly on the wages of unskilled workers. This suggests a relative skilled labor intensity in the production of these goods. ${ }^{19}$

Interestingly, my results are consistent with the correlations that are implied by the multidimensional version of the Stolper-Samuelson theorem. According to my estimates, Food and Beverages and Clothing are revealed to be relatively low-skill intensive goods, while House Equipment (appliances, chemicals) is revealed to be relatively skill-intensive goods. Looking at employment data on the EPH (Permanent Household Survey), Table 4 reports evidence that supports this conclusion. It shows that $76.4 \%$ of the workforce employed in Food and Beverages is of low skills, while $4.4 \%$ is of high skills; for Clothing, the shares are $73.6 \%$ and $2.2 \%$ respectively. In contrast, $67.9 \%$ of the workforce employed in House Equipment comprises unskilled labor and 5.4\%, skilled labor. This evidence indicates higher proportions of skilled labor over unskilled labor in House Equipment than in Food and Beverages and Clothing.

\footnotetext{
${ }^{19}$ I have extensively examined the robustness of the wage price-elasticities. The benchmark regression in Table 3 includes some basic controls such as age, age squared, marital status, gender and education dummies. The results for the controls are as I might expect; a male is likely to earn a higher wage than a female (39.7\% higher, actually) and a married person earns a $13.9 \%$ higher wage than a single individual. Experience, as measured by a polynomial in age, and education also have the usual positive effect on wages. I have tried a variety of variable included to control for additional determinants of wages (technical progress and factor endowments): time trends, no controls, yearly dummy variables, and dummies identifying whether observations come from May or October. The general picture that emerges from all these regressions is very similar to the picture described in Table 3. There are, of course, some minor differences in magnitudes but none in the signs. These results suggest that the findings are robust.
} 
Table 4

Factor intensities by skills Argentina 1996

\begin{tabular}{llrr}
\hline & Food and beverages & Clothing & House equipment \\
\hline Primary education (unskilled labor) & 76.40 & 73.60 & 67.90 \\
Secondary education (semiskilled labor) & 19.20 & 24.20 & 26.70 \\
College education (skilled labor) & 4.40 & 2.20 & 5.40 \\
\hline
\end{tabular}

The numbers are the proportion of each type of labor (unskilled, semiskilled, skilled) on total labor employment in the different sectors.

Source: Permanent Household Survey (EPH).

Finally, there is evidence supporting a multidimensional version of the magnification effects, according to which factor prices would react more than proportionately to price changes. These magnification effects explain why some of the wage price-elasticities are relatively large. Leamer (1996), Baldwin and Cain (1997) and Grossman and Levinsohn (1989) have found similar magnitudes.

\subsubsection{Distributional effects}

The average distributional effects at different levels of income are displayed in Fig. 3. The estimation of the confidence bands also requires bootstrap methods. As I explained before, I want to make the consumption effects comparable to the labor income effects. This means that the households used in the distributional analysis are those interviewed in the expenditure survey (ENGH). Thus, I resample from the ENGH survey. To deal with the variance of the estimated wage price-elasticities, I take samples of these elasticities from the asymptotic distribution $\hat{\boldsymbol{\beta}}_{\mathbf{2}} \rightarrow{ }^{d} N$ $\left(\boldsymbol{\beta}_{\mathbf{2}}, \boldsymbol{\Omega}_{\mathbf{2}}\right)$, where $\boldsymbol{\beta}_{\mathbf{2}}$ is the vector of parameters and $\boldsymbol{\Omega}_{\mathbf{2}}$ is the variance. I assign these bootstrapped elasticities to the resampled ENGH households and I rerun the Fan regressions on these samples. After 200 loops, I estimate the interquantile range of the distributional effects (at each income level) to build the confidence bands.

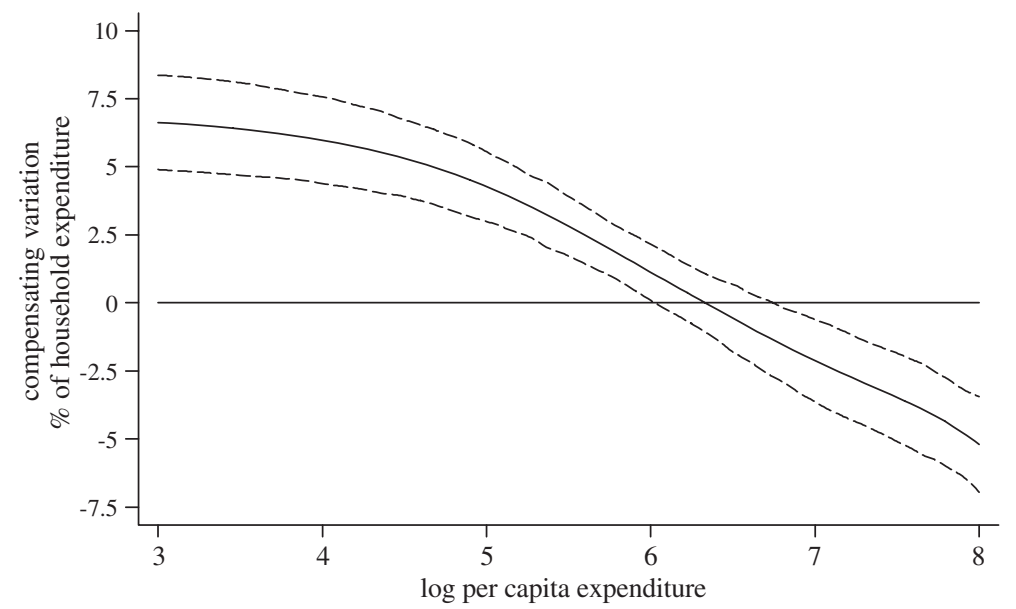

Fig. 3. Labor income effects of Mercosur. Notes: the solid line shows the average labor income effect of Mercosur. The curve is estimated with locally weighted non-parametric regression (Fan, 1992). The broken lines report the 5\% confidence bands of the average consumption effects. These bands are estimated with bootstrap methods (see text). 


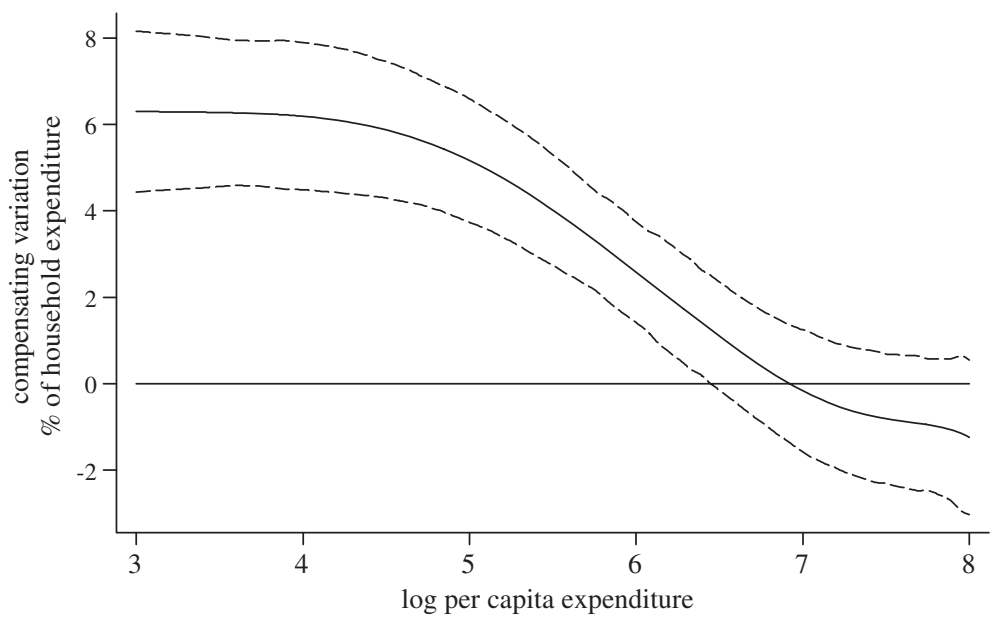

Fig. 4. Total welfare effects. Notes: the solid line shows the average total welfare effect (labor income effects, consumption effects of traded goods, and consumption effects of non-traded goods). The curve is estimated with locally weighted nonparametric regression (Fan, 1992). The broken lines report the $5 \%$ confidence bands of the average consumption effects. These bands are estimated with bootstrap methods (see text).

In what follows, I focus on the labor income effects of the household head. ${ }^{20}$ Fig. 3 plots the average total welfare effects caused by the reaction of wages to the changes in the four prices of traded goods (together with the confidence bands). I find that Mercosur has a positive effect on the average labor income of the poor and a negative effect on the average labor income of the rich: the distributional curve slopes downward and the average compensating variations are significantly different from zero, and significantly different across income levels. The magnitudes are important: while the gains, for middle-income to poor households, can reach $7 \%$ of their initial expenditure, the losses, for rich households, can reach $5 \%$ of initial expenditure.

There is a simple explanation for these results, which is based on the revealed factor intensity of the traded goods. Mercosur brings about changes in tariffs on traded goods that generate an increase in the relative price of unskilled intensive goods (mainly due to the increase in the price of Food and Beverages and the larger decline in the price of House Equipment). These induced price movements impact negatively on the wages of more skilled workers and positively on the wages of less educated individuals, producing a pro-poor bias.

\subsection{The total distributional effects of Mercosur}

The fundamental result of my investigation is reported in Fig. 4, which displays the total distributional impacts of Mercosur, the sum of consumption effects (traded and non-traded) and labor income effects, across the entire distribution of income. I find that Mercosur produces welfare gains for the average Argentine household almost across the entire income distribution.

\footnotetext{
${ }^{20}$ For some households in the sample, there is more than one working member. To account for their role in the welfare effects, I need information on the share of income earned by each household member, which is not available in the ENGH Survey. I therefore focus here on the household head, the major source of reported income by Argentine households. A more complete analysis, including the responses of the labor income of the head and non-head members together with capital income can be found in Porto (2002). The results remain mainly unchanged.
} 
Whereas the gains are statistically significant for poor and middle-income households, the welfare effects are negative, but not significant, at the upper tail of the income distribution. In addition, the gains are significantly higher for the average poor household in the country, indicating that Mercosur has had pro-poor distributional effects. In fact, the average compensating variation for the poor amounts to up to 6 percent of initial expenditure, whereas for middle-income households the gains amount to around $3 \%$.

Given the trends of increasing poverty and inequality observed in Argentina during the 1990s, these findings have to be put into context. They indicate that the changes in tariffs on consumption goods adopted in Mercosur cause the relative price of unskilled intensive goods to increase. The Stolper-Samuelson correlations then dictate an increase in the wages of unskilled workers and a decline in the wages of skilled workers. Consumption effects are also important and favor rich families, but the magnitudes are not large enough to outweigh the pro-poor labor income effects (except for the very rich families).

In this distributional analysis, I have only examined the effects of changes in Mercosur tariffs. The role of non-labor income (profits, capital) and unemployment has not been considered. Other shocks, like the Brazilian devaluation, exogenous changes in international prices, and concurrent domestic reforms, have not been addressed either. Further, notice that the impacts estimated in the paper are relatively small, with gains of, at most, $6 \%$ of initial expenditure. It is certainly plausible that all the other reforms introduced in the country, together with some unmeasured effects of Mercosur, outweigh the progressive impacts of the changes in tariffs on consumption goods. My conclusion is that without the tariff changes originating in the regional trade agreement, poverty in Argentina would have been still higher.

I turn now to explore the implications of the unitary pass-through assumption. Even though estimating pass-through rates is beyond the scope of this paper, it is important to ask how sensitive results are to changes in these assumptions. Notice, first, that if the pass-through rates for

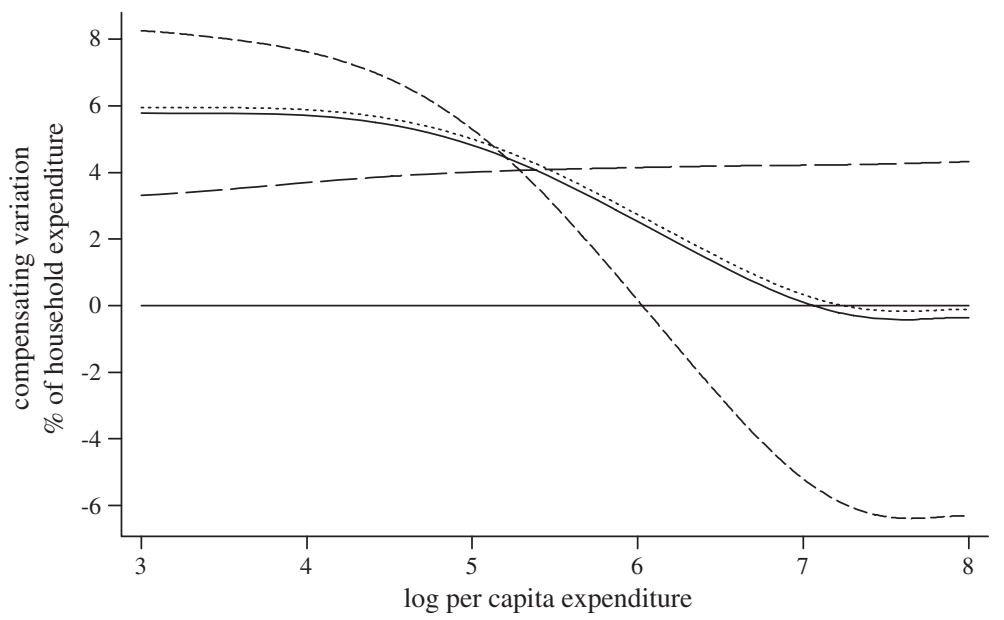

Fig. 5. Sensitivity analysis. Notes: the figure reports four curves representing the total welfare effects of Mercosur (labor income and consumption effects) under different pass-through rate assumptions. In each scenario, three pass-through rates are kept at unity and the remaining rate is reduced to 0.7. In the solid curve, the reduced rate is for Food and Beverages; in the dotted curve, the reduced rate is for Other Goods; in the small dash curve, the reduced rate is for Clothing; and in the long dash curve, the reduced rate is for House Equipment. The curves are estimated with locally weighted non-parametric regression (Fan, 1992). 
all goods are reduced proportionally, then there is a level effect in the distributional impacts of Fig. 4. That is, they are just proportionally re-scaled. For instance, working with pass-through rates of 0.7 instead of 1 would cause a decline of the gains of the poor from around $6 \%$ to around $4.2 \%$ ( 0.7 times 6$)$. However, assuming a different pass-through rate for the different goods has more important implications because both the magnitudes and the distributional consequences could be affected. To see this, I propose to perform a sensitivity analysis whereby I estimate the total distributional effects of Mercosur in four scenarios. In each of these scenarios, I keep three pass-through rates at unity and the remaining rate is reduced to 0.7 .

The results are reported in Fig. 5. In the solid curve, the reduced rate is for Food and Beverages; in the dotted line, the reduced rate is for Other Goods; in the small dash curve, the reduced rate is for Clothing; and in the long dash curve, the reduced rate is for House Equipment. Changes in the pass-through rate for Food and Beverages and Other Goods do not affect my conclusions. If, instead, the pass-through rate for Clothing is reduced, the findings are reinforced. In fact, whereas the gains of the poor become more pronounced, the losses of the rich become now higher. The reason is that Clothing is a relatively unskilled intensive good so that a smaller price decline (implied by the lower pass-through) benefits unskilled labor and hurt skilled workers. In the case of House Equipment, a lower pass-through rate flattens the curve that describes the distributional effects. This is because House Equipment is relatively skilled intensive good and a lower price decline due to a lower pass-through benefits them. Overall, thus, different assumptions on pass-through rates will affect the magnitudes of the distributional effects of Mercosur, but do not change the broad conclusions of this study in a significant way.

\section{Concluding comments}

In this paper, I have developed a methodology to estimate the distributional effects of trade policies (and other pricing policies in general) in developing countries. The methodology is characterized by a very intensive use of household survey data, an approach seldom followed in the assessment of trade policies in the related literature. In addition, the paper has looked at the general equilibrium effects of trade reforms using econometric techniques, rather than Computable General Equilibrium modeling. This has allowed for a more important role for measurement, as opposed to assumptions, in the estimation of the distributional impacts of trade policies. Importantly, the use of household survey data has allowed me to explore the distributional analysis of trade reforms across the entire income distribution.

My general equilibrium welfare analysis builds on the estimation of the household compensating variations that would leave each Argentine family indifferent to the situation before the policy change. I have measured consumption effects, as consumers pay different prices for traded and non-traded goods, and labor income effects, as factor prices react to trade policies. The methodology has been applied to the study of the distributional impacts of the adoption of a regional trade agreement like Mercosur. The procedure can, in principle, be also applied to the experiences of other developing countries.

I have found that Mercosur has had pro-poor distributional effects. The reason is that Argentine trade policy protected the rich over the poor, prior to the reform, and granted some protection to the poor, after the reform. As a result, the relative pre-Mercosur tariff is higher on relatively skilled intensive goods. This means that tariff removals would tend to benefit the poor over the rich. These findings indicate that trade has not been responsible for the increase in poverty and income inequality observed in Argentina during the 1990s, at least in terms of the protection granted to final goods. The 
role of other factors and policies, such as deregulation, privatization, social security reforms, labor market reforms, monetary stabilization and industrial policy is yet to be explored.

\section{Acknowledgement}

I wish to thank Angus Deaton and Gene Grossman for their comments, insights and continuous support. I also thank A. Case, A. Harrison, B. Honore, A. Menendez and M. Olarreaga for useful discussion. My special thanks go to Irene Brambilla. I have benefited from the comments of seminar participants at Berkeley, Georgetown, Harvard, Michigan, Princeton, Stanford and the World Bank. Remaining errors are my sole responsibility.

\section{Appendix A. The household expenditure (ENGH) survey}

The National Household Expenditure Survey (ENGH) contains data on consumption at the household level. In Argentina, the consumption classification involves nine groups of goods, with many subcategories in each group. These nine groups are Food and Beverages, Clothing, Housing, House Equipment, Entertainment, Education, Health, Transport and Communication, Other Goods and Services. The National Institute of Statistics and Censuses constructs price indices for these consumption goods.

The ENGH Survey, conducted from March 1996 to March 1997, provides information on household monthly expenditure on over ninety goods. For simplicity, I designate each of the minor categories of goods as a traded or a non-traded good and include them in one of the seven consumption aggregates in the text. Traded goods include Food and Beverages (including tobacco), Clothing (textiles, apparel and footwear), House Equipment and Maintenance Goods (chemicals, plastic, appliances), and Other Traded Goods. Non-traded goods include Housing, Transport and Communication, Health and Education, and Leisure Goods. I construct the price indexes for these seven aggregates as a geometric weighted average of the index prices of all subcategories, using budget shares in 1996 as weights.

The ENGH is a comprehensive survey that covers over 21,127 households (once outliers are eliminated) across urban areas in Argentina. Some basic features of the data are as follows. The mean household per capita expenditure in Argentina during 1996/1997 was 251.2 dollars per month, with a standard error of 246 dollars. Argentine households spent, on average, $47 \%$ of their budget on Food and Beverages. Housing, Transport and Communication accounted for $20.9 \%$ of the budget while Other Traded Goods accounted for another $8.5 \%$. 7.8\% of the average budget went to Clothing, $6.3 \%$ was spent on Health and Education and $5.7 \%$ was spent on Leisure Goods. Finally, 3.7\% of total household expenditure was allocated to House Equipment and Maintenance Goods.

\section{Appendix B. The permanent household survey}

In this Appendix, I describe the data used to estimate the wage price-elasticities. My method identifies these elasticities using a time series of household surveys and prices. In Argentina, the main source of labor market information is the Permanent Household Survey, Encuesta Permanent the Hogares, or EPH. These surveys are collected in May and October in each year.

The key insight of the empirical methodology is the use of the wage data in the EPHs with the price data for consumption goods. Identification comes from the time variation in prices and surveys. Specifically, I use data from 1992 to 1999, sixteen surveys in total. 
Table A.1 reports the average log wages, in each time period, for each of the three educational categories. In each time period, I observe that College graduates earned higher (average) wages than Secondary school graduates who, at the same time, earned higher wages than Primary school workers. The wages of primary and secondary school graduates grew until 1994, when they started to decline. The trend in the wages of skilled individuals is similar albeit with two distinct characteristics: the initial increase in wages at the beginning of the decades continued beyond 1994 and well into 1995, and the decrease after 1995 was somewhat attenuated.

Table A.1 also reports the time series of prices of the four traded goods, from 1992 to 1999. Two observations per year, corresponding to themonths ofMay and October (when the EPHs are collected), are shown. The price of Food and Beverages increased substantially during 1992 and 1993 and stabilized afterwards, albeit with a somewhat upward trend (except in 1999). There was a substantial decline in the price of Clothing during the 1990s. In contrast, the price of House Equipment remained relatively stable through time, whereas the price of other goods showed an upward trend.

Table A.1

Average wages and prices in Argentina: 1992-1999

\begin{tabular}{|c|c|c|c|c|c|c|c|c|}
\hline & \multicolumn{3}{|l|}{ Wages } & \multicolumn{5}{|l|}{ Prices } \\
\hline & Unskilled & Semiskilled & Skilled & $\begin{array}{l}\text { Food and } \\
\text { Beverages }\end{array}$ & Clothing & $\begin{array}{l}\text { House } \\
\text { Equipment }\end{array}$ & $\begin{array}{l}\text { Other } \\
\text { Goods }\end{array}$ & $\begin{array}{l}\text { Sample } \\
\text { Size }\end{array}$ \\
\hline May 1992 & 5.716 & 6.026 & 6.368 & 76.2 & 83.9 & 88.0 & 88.1 & 19695 \\
\hline Oct 1992 & 5.809 & 6.130 & 6.485 & 83.8 & 83.5 & 91.7 & 93.0 & 20830 \\
\hline May 1993 & 5.883 & 6.193 & 6.575 & 88.1 & 82.8 & 93.6 & 97.6 & 22934 \\
\hline Oct 1993 & 5.924 & 6.253 & 6.628 & 90.7 & 80.3 & 93.7 & 101.4 & 22777 \\
\hline May 1994 & 5.871 & 6.233 & 6.650 & 87.8 & 79.6 & 93.2 & 105.2 & 28636 \\
\hline Oct 1994 & 5.890 & 6.258 & 6.678 & 91.0 & 78.7 & 93.3 & 107.8 & 28645 \\
\hline May 1995 & 5.887 & 6.269 & 6.716 & 91.2 & 78.1 & 95.2 & 109.8 & 27377 \\
\hline Oct 1995 & 5.825 & 6.231 & 6.681 & 93.0 & 75.3 & 96.1 & 110.2 & 31575 \\
\hline May 1996 & 5.802 & 6.225 & 6.647 & 91.1 & 73.2 & 93.7 & 110.0 & 33459 \\
\hline Oct 1996 & 5.772 & 6.190 & 6.644 & 93.0 & 70.7 & 93.3 & 109.5 & 30304 \\
\hline May 1997 & 5.749 & 6.201 & 6.664 & 90.4 & 69.1 & 92.8 & 109.4 & 35134 \\
\hline Oct 1997 & 5.754 & 6.189 & 6.687 & 92.7 & 67.1 & 92.6 & 109.1 & 35051 \\
\hline May 1998 & 5.783 & 6.201 & 6.718 & 93.6 & 66.4 & 93.0 & 108.9 & 32840 \\
\hline Oct 1998 & 5.765 & 6.215 & 6.744 & 93.8 & 63.6 & 93.0 & 108.4 & 31027 \\
\hline May 1999 & 5.697 & 6.158 & 6.694 & 89.6 & 62.4 & 92.6 & 108.1 & 28070 \\
\hline Oct 1999 & 5.690 & 6.138 & 6.657 & 88.2 & 59.1 & 92.1 & 107.9 & 27718 \\
\hline
\end{tabular}

Source: Wages (expressed in logs) come from the Permanent Household Survey (EPH). Prices are reported by the National Institute of Statistic and Census (INDEC). The price data refer to the price index of the main categories of consumption goods in the National Household Expenditure Survey (ENGH) in Argentina.

\section{References}

Armington, P.S., 1969. A theory of demand for products distinguished by place of production. IMF Staff Papers 16, $159-176$.

Attanasio, O., Goldberg, P., Pavcnik, N., 2004. Trade reforms and income inequality in Colombia. Journal of Development Economics 74, 331-366.

Baldwin, R.E., Cain, G.C., 1997. Shifts in US Relative Wages: The Role of Trade, Technology, and Factor Endowments. NBER Working Paper No 5934.

Deaton, A., 1981. Optimal taxes and the structure of preferences. Econometrica 49, 1245-1260.

Deaton, A., 1987. Econometric issues for tax design in developing countries. In: Newbery, D.M., Stern, N. (Eds.), The Theory of Taxation for Developing Countries. Oxford University Press, New York, pp. 92-113. 
Deaton, A., 1989. Rice prices and income distribution in Thailand: a non-parametric analysis. Economic Journal 99, 1-37.

Deaton, A., 1997. The Analysis of Household Surveys. A Microeconometric Approach to Development Policy. John Hopkins University Press for the World Bank.

Dixit, A., Norman, V., 1980. Theory of International Trade. A Dual, General Equilibrium Approach. Cambridge Economic Handbooks.

Edmonds, E., Pavcnik, N., 2005. The effects of trade liberalization on child labor. Journal of International Economics 65 , 401-419.

Fan, J., 1992. Design-adaptive nonparametric regression. Journal of the American Statistical Association 87, 998-1004.

Friedman, J., Levinsohn, J.A., 2002. The distributional impacts of Indonesia's financial crisis on household welfare: a 'rapid response' methodology. World Bank Economic Review 16, 397-423.

Gasparini, L., 1999. Desigualdad en la Distribución del Ingreso y Bienestar. Estimaciones Para Argentina. FIEL, Buenos Aires, Argentina.

Goldberg, P., Pavcnik, N., 2005. Trade, wages, and the political economy of trade protection: evidence from the Colombian trade reforms. Journal of International Economics 66, 75-105.

Goldberg, L., Tracy, J., 2003. Exchange Rates and Wages. Federal Reserve Bank of New York, mimeo.

Grossman, G., Levinsohn, J., 1989. Import competition and the stock market return to capital. American Economic Review 198, 1065-1087.

Hicks, J., 1939. Value and Capital. Clarendon Press, Oxford.

Kloek, T., 1981. OLS estimation in a model where a microvariable is explained by aggregates and contemporaneous disturbances are equicorrelated. Econometrica 49, 205-207.

Leamer, E., 1996. In Search of Stolper-Samuelson Effects on US Wages. NBER WP No 5427.

Mas-Collel, A., Whinston, M., Green, J., 1995. Microeconomic Theory. Oxford University Press, New York.

Porto, G., 2002. The Distributional Effects of Mercosur. Unpublished Ph.D. Dissertation, Princeton University.

Porto, G., 2005. Informal export barriers and poverty. Journal of International Economics 66, 447-470.

Ravallion, M., 1990. Rural welfare effects of food price changes under induced wage responses: theory and evidence for Bangladesh. Oxford Economic Papers 42, 574-585.

Shoven, J., Whalley, J., 1992. Applying General Equilibrium. Cambridge University Press, New York.

Whalley, J., 1985. Trade Liberalization Among Major World Trading Areas. MIT Press, Cambridge.

Wolak, F.A., 1996. The welfare impacts of competitive telecommunications supply: a household-level analysis. Brookings Papers on Economic Activity Microeconomics 269-340.

Wooland, A.D., 1982. International trade and resource allocation. Advanced Textbooks in Economics, vol. 19. North Holland, Amsterdam. 